\title{
THE COVID-19 PANDEMIC — A VIEW OF THE CURRENT STATE OF THE PROBLEM
}

\author{
Kurt Ruetzler ${ }^{1}$, Lukasz Szarpak ${ }^{2,3}$, Krzysztof Jerzy Filipiak', \\ Jerzy Robert Ladny ${ }^{3,5}$, Jacek Smereka ${ }^{3,6}$ \\ ${ }^{1}$ Departments of General Anesthesiology and Outcomes Research, Cleveland Clinic, Anesthesiology Institute, Cleveland, OH, USA \\ ${ }^{2}$ Lazarski University, Medical Simulation Centre, Warsaw, Poland \\ ${ }^{3}$ Polish Society of Disaster Medicine, Warsaw, Poland \\ ${ }^{4} 1^{\text {st }}$ Chair and Department of Cardiology, Medical University of Warsaw, Warsaw, Poland \\ ${ }^{5}$ Clinic of Emergency Medicine, Medical University of Bialystok, Bialystok, Poland \\ ${ }^{6}$ Department of Emergency Medical Service, Wroclaw Medical University, Wroclaw, Poland
}

KEY WORDS: SARS-SoV-2, COVID-19, medicine, pandemic, health care

The current pandemic has raised great global public health concern. The disease name was subsequently recommended as COVID-19 by the World Health Organisation (WHO) [1,2]. Meanwhile, 2019-nCoV was renamed SARS-CoV-2 by the International Committee on Taxonomy of Viruses. SARS-CoV-2 is considered highly contagious. As of April 1, 2020, more than 883,255 confirmed cases, including more than
44,156 deaths, have been reported worldwide, affecting almost the whole world. The distribution of countries with confirmed cases of the newly identified coronavirus SARS-CoV-2 infection as of 1 April 2020 is presented in Figure 1. Originally the epicentre of this ongoing outbreak was located in the city of Wuhan in Hubei Province of central China, and the Huanan seafood wholesale market was thought to be

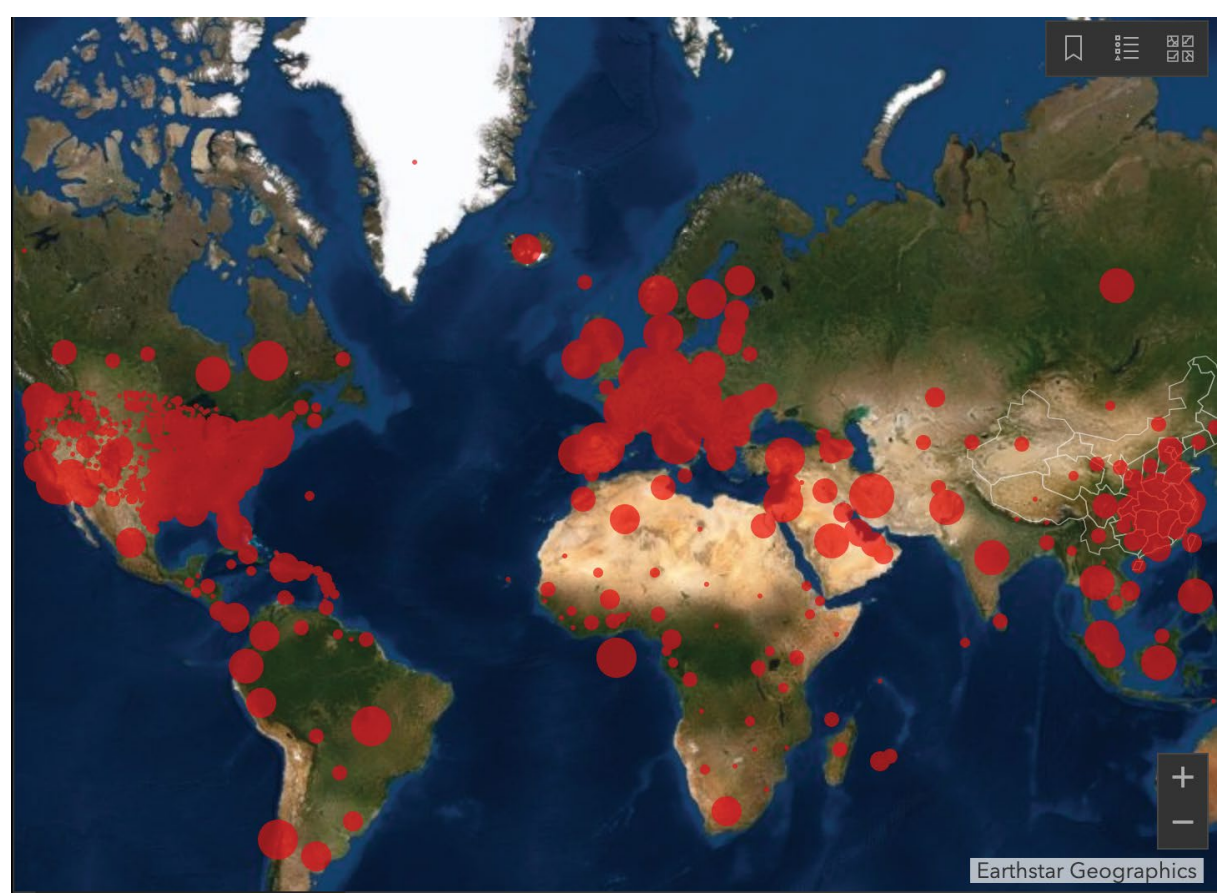

FIGURE 1. Distribution of countries with confirmed cases of the newly identified coronavirus SARS-CoV-2 infection as of 1 April 2020 according to the gisanddata.maps.arcgis.com. 
at least one of the places where SARS-CoV-2, from an unknown animal source, might have crossed the species barrier to infect humans. Italy and Spain are now considered the European epicentre of COVID-19; as of 1 April 2020, the number of cases in these countries is as follows: 105,792 and 102,136 confirmed infections, and 9,053 and 3,523 deaths, respectively. In the USA, the number of confirmed infections exceeds 189,753 cases. The SARS-CoV-2 coronavirus spreads mainly through respiratory droplets. COVID-19 is similar to SARS and MERS in some clinical manifestations. In COVID-19 patients, fever, cough, and myalgia are the most common symptoms, followed by chest distress and shortness of breath. However, upper respiratory tract symptoms (e.g. nasal congestion, nasal discharge, and sore throat) and gastrointestinal symptoms (e.g. abdominal pain and diarrhoea) are relatively rare. Fever occurs in 98$100 \%$ of SARS or MERS patients, compared to $81.3 \%$ of COVID-19 patients in this study [3]. Analysis of numerous studies [1, 4-12], covering 1991 patients, identified the most common signs and symptoms at admission to hospital. These symptoms include: dry cough $(63.9 \%)$, fever (61.7\%), fatigue and muscle ache (36.9\%), anorexia (27.1\%), dyspnoea (21.9\%), headache $(13.2 \%)$, sore throat $(12.0 \%)$, chest pain $(6.4 \%)$, confusion $(6.1 \%)$, rhinorrhoea $(6.0 \%)$, nausea and vomiting $(5.8 \%)$, and diarrhoea (5.3\%). As we can observe, the clinical picture of people infected with COVID-19 may present itself in a variety of ways; however, special attention should be paid to patients with such symptoms, and they should be subjected to screening and isolation until the results are obtained $[13,14]$. At the same time, it is worth emphasising that, as well as searching for a vaccine, it is crucial to constantly analyse the existing symptoms in order to verify new ones that may be reported by patients and which have not yet been taken into account in the clinical picture of the patient.

\section{Conflict of interest:}

The authors declare that they have no conflict of interest.

\section{Acknowledgements:}

Study was supported by the Polish Society of Disaster Medicine.

\section{REFERENCES}

1. Guan WJ, Ni ZY, Hu Yu, et al. China Medical Treatment Expert Group for Covid-19. Clinical Characteristics of Coronavirus Disease 2019 in China. N Engl J Med. 2020 [Epub ahead of print], doi: 10.1056/ NEJMoa2002032, indexed in Pubmed: 32109013.

2. Zhu Na, Zhang D, Wang W, et al. China Novel Coronavirus Investigating and Research Team. A Novel Coronavirus from Patients with Pneumonia in China, 2019. N Engl J Med. 2020; 382(8): 727-733, doi: 10.1056/NEJMoa2001017, indexed in Pubmed: 31978945.

3. Assiri A, Al-Tawfiq JA, Al-Rabeeah AA, et al. Epidemiological, demographic, and clinical characteristics of 47 cases of Middle East respiratory syndrome coronavirus disease from Saudi Arabia: a descriptive study. Lancet Infect Dis. 2013; 13(9): 752-761, doi: 10.1016/ S1473-3099(13)70204-4, indexed in Pubmed: 23891402.

4. Chen N, Zhou M, Dong X, et al. Epidemiological and clinical characteristics of 99 cases of 2019 novel coronavirus pneumonia in Wuhan, China: a descriptive study. The Lancet. 2020; 395(10223): 507-513, doi: 10.1016/s0140-6736(20)30211-7.

5. Huang $C$, Wang $Y$, Li $X$, et al. Clinical features of patients infected with 2019 novel coronavirus in Wuhan, China. The Lancet. 2020; 395(10223): 497-506, doi: 10.1016/50140-6736(20)30183-5.

6. Xu XW, Wu XX, Jiang XG, et al. Clinical findings in a group of patients infected with the 2019 novel coronavirus (SARS-Cov-2) outside of Wuhan, China: retrospective case series. BMJ. 2020; 368: m606, doi: 10.1136/bmj.m606, indexed in Pubmed: 32075786.

7. Wang D, Hu Bo, Hu C, et al. Clinical Characteristics of 138 Hospitalized Patients With 2019 Novel Coronavirus-Infected Pneumonia in Wuhan, China. JAMA. 2020 [Epub ahead of print], doi: 10.1001/ jama.2020.1585, indexed in Pubmed: 32031570.

8. Liu M, He P, Liu HG, et al. [Clinical characteristics of 30 medical workers infected with new coronavirus pneumonia]. Zhonghua Jie He He Hu Xi Za Zhi. 2020; 43(3): 209-214, doi: 10.3760/cma. j.issn.1001-0939.2020.03.014, indexed in Pubmed: 32164090.

9. Yuan $M$, Yin $W$, Tao $Z$, et al. Association of radiologic findings with mortality of patients infected with 2019 novel coronavirus in Wuhan, China. PLoS One. 2020; 15(3): e0230548, doi: 10.1371/journal. pone.0230548, indexed in Pubmed: 32191764.

10. Chen J, Qi T, Liu Li, et al. Clinical progression of patients with COVID-19 in Shanghai, China. J Infect. 2020 [Epub ahead of print], doi: 10.1016/j. jinf.2020.03.004, indexed in Pubmed: 32171869.

11. Mo $P, X i n g Y, X i a o ~ Y u$, et al. Clinical characteristics of refractory COVID-19 pneumonia in Wuhan, China. Clin Infect Dis. 2020 [Epub ahead of print], doi: 10.1093/cid/ciaa270, indexed in Pubmed: 32173725.

12. Qian GQ, Yang NB, Ding F, et al. Epidemiologic and Clinical Characteristics of 91 Hospitalized Patients with COVID-19 in Zhejiang, China: A retrospective, multi-centre case series. QJM. 2020 [Epub ahead of print], doi: 10.1093/qjmed/hcaa089, indexed in Pubmed: 32181807.

13. Smereka J, Szarpak L. COVID 19 a challenge for emergency medicine and every health care professional. The American Journal of Emergency Medicine. 2020, doi: 10.1016/j.ajem.2020.03.038.

14. Smerek J, Szrpk L, Filipik KJ. Modern medicine in COVID-19 er. Disster Emerg Med J 2020. Doi: 10 5603/DEMJ a. 2020; 0012, doi: 10.5603/ DEMJ.a2020.0012. 